\title{
Prevalence of depression in mothers of children suffering from psychiatric and physical disorders
}

\author{
H Perera $^{1}$, C D K Mudalige ${ }^{2}$, H M P P Karunaweera ${ }^{2}$, K Wanigasinghe ${ }^{3}$, VI Dharmawardena ${ }^{2}$, \\ H Jayasekara ${ }^{4}$, K Ratnayake ${ }^{4}$ \\ Sri Lanka Journal of Child Health, 2008; 37: 42-7
}

(Key words: depression, stress, mothers, mental disorders, physical disorders)

\begin{abstract}
Background Adverse impact of child mental disorders on the mental health of mothers is reported from other parts of the world but data is not from South Asia.

Objectives To study the prevalence of depression among mothers seeking help for mental disorders in their children and compare it with that of mothers whose children are receiving treatment for physical disorders.
\end{abstract}

Method Depression in mothers was assessed using self-rating and observer-rating standardized scales. The opinions of mothers regarding sensitivity to child and sense of behaviour control were also assessed.

Results Prevalence in both groups of mothers was twice that of adult women in the community with regard to moderate and severe depression. Proportionately more mothers with mentally disordered children felt less sensitive towards the child, less in control of behaviour, and less supported by others when compared to those with physically disordered children.

Conclusions Mothers of mentally disordered children should be screened for depression, stress and poor coping.

\section{Introduction}

Parents of children with behavioural disorders, emotional problems, learning disabilities and

\footnotetext{
${ }^{1}$ Professor, Department of Psychological Medicine, University of Colombo, ${ }^{2}$ Senior Registrar, Psychiatry, ${ }^{3}$ Medical Officer, Psychiatry, ${ }^{4}$ Registrar, Psychiatry
}

(Received on 27 November 2007. Accepted on 20 December 2007) developmental disorders are vulnerable to develop mental health problems themselves due to the high caretaking demand and stress imposed on them. The most widely studied behaviour disorder in children, with a substantial impact on parent mental health, is attention deficit hyperactivity disorder (ADHD) $)^{1,2}$. The mother, rather than the father, has been the focus of attention in many studies, perhaps due to the greater role she plays in child rearing and higher level of contact with children. The recognized impact include feeling stigmatized and socially isolated ${ }^{3,4}$. Certain personal characteristics in mothers have been identified as determinants of the psychological impact they experience. Those less skilled in controlling their children's behaviour, having less knowledge about the illness 5 , interpret the behaviour as deliberate non-compliance and are more likely to be stressed and depressed ${ }^{6}$. Illness characteristics in the child, add towards maternal stress and depression $^{7,8}$.

The impact of physical illness in children on the mental health of their mothers also has been studied, mainly in relation to life threatening and disabling conditions $^{9}$. Anxious personality traits in mothers are found to make them most vulnerable in this regard, because their psychological state undermines the coping ability ${ }^{10}$. Excess of risk factors for depression have been identified in mothers of children with birth defects. These risk factors include feelings of guilt, pathological attachment to the child, presence of chronic tension, social isolation, marital problems and conflict with medical staff ${ }^{11}$ Co-existing behaviour problems predicts higher levels of stress in the mothers of physically ill children ${ }^{12}$. In addition, mental health is adversely affected in mothers of children with chronic illness especially when the time taken for diagnosis is prolonged and the quality relationship with medical staff is poor ${ }^{13}$.

The above mentioned research data come from industrialized countries where state sponsored social care systems and other support services are available 
for parents of children with behaviour problems and disabilities. Such social care is not available to mothers in Sri Lanka, although the illness in the child that is studied and the predisposing circumstances and risks are no different in the two settings. There is no data available from South Asia on mental health problems in mothers of children with illness or disability, though relevant to clinical care of the children. As the focus of clinical care is singularly on the ill child, identifying mothers with depression is often missed, except in extreme situations. This study is aimed at estimating the prevalence of depression in mothers and their attitude towards the child's illness.

\section{Objectives}

- To estimate the prevalence of depression in mothers of children seen in a specialist child mental health service.

- To study the relationship between the illness characteristics in the child with a mental disorder and depression in the mother.

- To study the quality of the emotional response and the relationship the mother has towards the child with a mental disorder.

- To compare the above findings on similar variables with that of mothers of children with physical disorders.

\section{Method}

Study sample comprised mothers of all children, referred to a specialist mental health outpatient service in a tertiary care paediatric hospital, during a period of 3 months in 2005, and who received a diagnosis of a mental disorder. The assessment was carried out on the first visit for consultation.

Comparative sample comprised mothers of children who were receiving inpatient care in the same tertiary care paediatric hospital for a physical disorder. These mothers were selected in two stages. In the first stage, six medical and surgical units in the hospital were randomly selected. In the second stage, mothers of children in each medical or surgical unit were randomly allocated to the study. Children suffering from severe physical disabilities, burns and trauma were excluded from the study as these children were likely to have clinically significant psychological disturbances and would create difficulty in comparing the two samples.

\section{Main measures}

1. Presence of depression in both samples of mothers was assessed using the Beck Depression Inventory and the Hamilton Depression Scale.

- Beck Depression Inventory is a self rated standardized questionnaire in English, designed to identify depression. This was translated into Sinhala and was found to have a satisfactory reliability on testing. The questionnaire was completed by all mothers included in the study.

- Hamilton Depression Scale is an observer rated standardized scale in English. The scale was administered to the mother by the authors of this study. The authors agreed among themselves on uniformity in posing the questions to nonEnglish speaking mothers. The individual items on the scale were checked for cultural validity and were found to be satisfactory.

2. The following data was gathered on all the mothers:

- Socio-demography

- $\quad$ Presence of a past history and/or a family history of depression

- $\quad$ Presence of a physical illness

- The opinion of the mother regarding the level of behaviour control she had on the child, recoded on a three point scale.

- The opinion of the mother regarding the level of sensitivity she felt towards the child's health problem, recorded on a three point scale.

- Opinion of mother regarding the availability of social support for management of the child, recorded on a three point scale.

3. The following data was gathered from mother regarding the child

- $\quad$ Age of the child.

- The nature and duration of the main health problem in the child.

- Profile of the symptoms indicating a mental health problem in the child and classified as conduct, emotional or developmental. 
- The opinion of the mother regarding the impact of the main health problem on the general functioning of the child, recorded on a three point scale.

In assessment of general functioning in the child, the areas that were considered were, play, school attendance, relationship with peers, relationship with family members and quality of sleep.
The interviews were carried out by the authors. Items 2 and 3 above were tested and found to have satisfactory inter-rater reliability. Informed voluntary consent was obtained from mothers to administer the assessment tools and gather data. Ethical clearance was obtained for the study. Data analysis was done using the software SPSS version 15.

\section{Results}

Table 1

Comparison of the characteristics of mothers of children with mental health problems and physical problems regarding demography and history of illness

\begin{tabular}{|l|c|c|}
\hline \multicolumn{1}{|c|}{ Variable regarding mother } & $\begin{array}{c}\text { Child has a mental } \\
\text { disorder } \mathbf{N = 7 0}\end{array}$ & $\begin{array}{c}\text { Child has a physical disorder } \\
\mathbf{N}=\mathbf{6 4}\end{array}$ \\
\hline Mean age & 37.7 years $(27-58)$ & 31.5 years $(18-49)$ \\
\hline Employment status & $16(22.8 \%)$ & $12(18.8 \%)$ \\
- employed & $54(77.2 \%)$ & $52(81.1 \%)$ \\
- housewife & $09(12.9 \%)$ & $08(12.5 \%)$ \\
\hline Highest educational level & $59(84.3 \%)$ & $54(84.4 \%)$ \\
- primary & $02(02.9 \%)$ & $01(01.6 \%)$ \\
- secondary & $03(04.3 \%)$ & $0(0 \%)$ \\
- tertiary and above & $67(95.7 \%)$ & $64(100 \%)$ \\
\hline Past H/O treatment for depression & & $04(06.3 \%)$ \\
- yes & $05(07.1 \%)$ & $60(93.8 \%)$ \\
- no & $65(92.9 \%)$ & $12(18.8 \%)$ \\
\hline Family H/O of depression & & $52(81.3 \%)$ \\
- yes & $22(31.4 \%)$ & \\
- no & $48(68.6 \%)$ & \\
\hline Presence of physical illness & & \\
- yes & & \\
- no & & \\
\hline
\end{tabular}

Table 2

Comparison of the characteristics of mothers of children with mental health problems and physical problems regarding behaviour control, sensitivity and availability of social support

\begin{tabular}{|l|c|c|}
\hline Variable regarding mother's opinion & $\begin{array}{c}\text { Child has a mental disorder } \\
\mathbf{N = 7 0}\end{array}$ & $\begin{array}{c}\text { Child has a physical disorder } \\
\mathbf{N}=\mathbf{6 4}\end{array}$ \\
\hline Behaviour control of child & $13(18.6 \%)$ & $55(86.0 \%)$ \\
- effective & $29(41.4 \%)$ & $08(12.5 \%)$ \\
- somewhat effective & $28(40.0 \%)$ & $01(01.6 \%)$ \\
- ineffective & $50(71.4 \%)$ & $59(92.2 \%)$ \\
\hline Sensitivity towards child & $16(22.9 \%)$ & $05(07.8 \%)$ \\
- sensitive & $04(05.7 \%)$ & $0(0 \%)$ \\
- moderately sensitive & $46(65.7 \%)$ & $49(76.6 \%)$ \\
- insensitive & $15(21.4 \%)$ & $08(12.5 \%)$ \\
\hline Availability of support from others & $09(12.9 \%)$ & $04(06.3 \%)$ \\
- good & & \\
- moderate & & \\
- poor & & \\
\hline
\end{tabular}


Table 3

Comparison of illness characteristics of children with mental disorders and physical disorders as reported by mothers

\begin{tabular}{|l|c|c|}
\hline \multicolumn{1}{|c|}{ Variable regarding the child } & $\begin{array}{c}\text { Child has a mental disorder } \\
\mathbf{N = 7 0}\end{array}$ & $\begin{array}{c}\text { Child has a physical } \\
\text { disorder } \mathbf{N}=\mathbf{6 4}\end{array}$ \\
\hline Mean age & 5.9 years & 4.5 years \\
\hline Presence of a mental health related & $100 \%$ & $13(20.3 \%)$ \\
symptoms & $07(10 \%)$ & $02(3.1 \%)$ \\
- conduct & $27(38.6 \%)$ & $06(9.4 \%)$ \\
- emotional & $09(12.9 \%)$ & $05(7.8 \%)$ \\
- developmental & $27(38.6 \%)$ & $0(0 \%)$ \\
- multiple & $17(24.3 \%)$ & $100 \%$ \\
\hline Presence of physical disorder & $53(75.7 \%)$ & $0(0 \%)$ \\
- yes & $22.8 \mathrm{months}$ & $5 \mathrm{months}$ \\
- no & & $23(35.9 \%)$ \\
\hline Mean duration of the problem & $04(05.7 \%)$ & $28(43.8 \%)$ \\
\hline Impact of illness on functional & $30(42.9 \%)$ & $13(20.3 \%)$ \\
level & $36(51.4 \%)$ & \\
- none & & \\
- moderate & & \\
- severe & & \\
\hline
\end{tabular}

The children with mental disorders had a longer duration of illness than the physically ill children. In addition nearly $1 / 4$ had a physical illness, epilepsy being the commonest.

Table 4

Comparison of depression scores and intensity of depression in mothers of mentally disordered and physically disordered children

\begin{tabular}{|l|c|c|}
\hline $\begin{array}{c}\text { Scores on Depression scales } \\
\text { and intensity of depression }\end{array}$ & $\begin{array}{c}\text { Prevalence in mothers of } \\
\text { mentally disordered children } \\
\text { N=70 }\end{array}$ & $\begin{array}{c}\text { Prevalence in mothers of } \\
\text { physically disordered children } \\
\text { N=64 }\end{array}$ \\
\hline Hamilton scores & $8.07(0-43)$ & $6.92(0-37)$ \\
Mean score & $54(77.1 \%)$ & $50(78.1 \%)$ \\
0 to $10-$ none / mild & $09(12.9 \%)$ & $10(15.6 \%)$ \\
11 to $20-$ moderate & $07(10,0 \%)$ & $04(06.3 \%)$ \\
over $21-$ severe & & \\
& & $18.56(13-37)$ \\
Beck scores & $18.71(13-41)$ & $50(78.1 \%)$ \\
Mean score & $53(75.7 \%)$ & $10(15.6 \%)$ \\
11 to $20-$ none / mild & $13(18.6 \%)$ & $04(06.3 \%)$ \\
21 to $30-$ moderate & $04(05.7 \%)$ & \\
over $30-$ severe & & \\
\hline
\end{tabular}

The correlation between scores from Beck and Hamilton scales was $r=0.624$ (p 0.000). Linear regression analysis did not identify statistically significant correlation between the depression scores in mothers and specific variables that were studied in the mother or the child. Independent $t$ Test showed that there was no significant difference between the depression scores in mothers of children with mental disorder and physical disorder $(\mathrm{p}>0.05)$.

\section{Discussion}

The known prevalence of current depression in adult women in primary health care setting is $10.4 \%{ }^{14}$. In our study, this figure was more than double for mothers of both mentally and physically disordered children, being $22.9 \%$ and $21.9 \%$ respectively for moderate to severe depression. The prevalence of depression in mothers of mentally disordered children was only slightly higher than the comparison group. This difference is more evident on self assessment of depression, but was not statistically significant ( $\mathrm{p}>0.5)$. 
In contrast, there were a number of differences between the two groups of mothers, although they were similar with regard to demographic, social and illness data. Firstly, proportionately more mothers with mentally disordered children reported feeling moderately sensitive and insensitive towards their children's problems than mothers of physically ill children $(22.9 \%$ and $7.8 \%$ versus $5.7 \%$ and $0 \%$ respectively). Secondly, a lower proportion of mothers with mentally disordered children felt they were effective enough in controlling their children's behaviour (18.6\% versus $86 \%$ ) and $40 \%$ versus $1.6 \%$ of these mothers reported that they felt totally ineffective in controlling their child's behaviour. Thirdly, more mothers of mental disordered children identified functional impairment in the child $(51.4 \%$ versus $20.3 \%$ ). Fourthly, reporting of physical illness was higher in mothers of mentally disordered children (31.4\% versus $18.8 \%$ ). Lastly, availability of social support was seen as low by more mothers of mentally disordered children (12.9\% versus $6.3 \%)$. These differences in the two groups may indicate that mothers of mental disordered children may suffer from considerably more emotional stress and anxiety than their counterparts. A related finding in this study, that may add to the emotional burden in these parents, is that help was sought only after the behaviour problems had existed for a considerably longer period on average when compared to duration of physical illnesses (22.8 months versus 5 months).

Supportive evidence for depression in mother with mental and physical health problems is already mentioned in the introduction to this article. Our findings on opinion, attitudes and sensitivity of mothers also replicate other studies. For instance, a mother may respond with less sympathetic toward a child with a behaviour problem if this is misinterpreted as deliberate non-compliance by the child $^{15,16,17}$; a distressed mothers have altered perception of the child's behaviour, lower tolerance for child's misconduct and feel less sensitive towards their children ${ }^{18}$; behaviour problems that are severe are more likely to give the parents a sense of incompetence in managing their children ${ }^{19}$.

\section{Limitations of the study}

The random selection of the comparison group limited the scope of selecting a matched sample with the main study group though difference was found regarding the demographic variables. Also, no attempt was made to match the mental disordered and physically disordered children in terms of the severity and duration of the illness.

\section{Clinical Relevance}

This study highlights the importance of screening for the impact of child mental disorders on mothers and providing support to optimize coping.

\section{Acknowledgement}

The authors sincerely appreciate the permission given by paediatricians and surgeons at Lady Ridgeway to interview their patients.

\section{References}

1. Harrison C, Sofronoff K. ADHD and parental psychological distress: role of demographic, child behavioural characteristics and parental cognitions. Journal of the American Academy of Child and Adolescent Psychiatry 2002; 41:703-11.

2. Befera M, Barkley R A. Hyperactive and normal boys and girls: mother-child interaction, parent psychiatric status, and child psychopathology. Journal of Child Psychology and Psychiatry 1985; 26:43952.

3. Norvilitis JM, Scime M, Lee JS. Courtesy stigma in mothers of children with Attention-Deficit/Hyperactivity Disorder: a preliminary investigation. Journal of Attention Disorder 2002; 6: 61-8.

4. Calam R, Bolton C, Roberts J. Maternal expressed emotion, attributions and depression and entry into therapy for children with behaviour problems. British Journal of Clinical Psychology 2002; 41: 213-6.

5. Mash E J, Johnston C. Determinants of parenting stress: illustrations from families of hyperactive children and families of physically abused children. Journal of Clinical Child Psychology 1990; 19:313-28.

6. Joiner T E, Wagner K D. Parental, childcentered attributions and outcome: a metaanalytic review with conceptual and methodological implications. Journal of Abnormal Child Psychology 1996; 24: 3752. 
7. Anastapoulos A, Guevremont D, Shelton T, DuPaul G. Parenting stress among families of children with attention deficit hyperactivity disorder. Journal of Abnormal Child Psychology 1992; 20: 503-22.

8. Podolski C L, Nigg J T. Parent stress and coping in relation to child ADHD severity and associated child disruptive behaviour problems. Journal of Clinical Child Psychology 2001; 30: 503-13.

9. Brown R T, Kaslow N J, Madan-Swain A, Doepke K J, Sexson S B, Hill L J. Parental psychopathology and children's adjustment to leukemia. Journal of the American Academy of Child and Adolescent Psychiatry 1993. 32: 554-61.

10. Hoekstra-Weebers J E H M, Jaspers J P C, Kamps W A, Klip C. Risk factors for psychological maladjustment of parents of children with cancer. Journal of the American Academy of Child and Adolescent Psychiatry 1999. 38: 1526-35.

11. Mayes L C, Gabriel H P, Oberfield R. Prematurity, birth defects and early death: impact on the family. In: Child and Adolescent Psychiatry, Ed: Melvin Lewis, Lippincott, Williams \& Wilkins, Baltimore 2002, 1123-35.

12. Nereo N E, Fee R J, Hinton V J. Parental stress in mothers of boys with Duchenne muscular dystrophy. Journal of Pediatric Psychology 2003; 28: 473-84.
13. Merelle M E, Huisman J, Aduden-van der Vecht A, Taat F, Bezemer D, Griffioen RW, et al. Early versus late diagnosis: psychological impact on parents of children with cystic fibrosis. Pediatrics 2003; 111: 346-50.

14. World Health Report 2001. Mental Health: new understanding, new hope. World Health Organization, Geneva, 21-45.

15. Anastopoulos A, Shelton T, DuPaul G, Guevremont D. Parent training for attention deficit hyperactivity disorder: its impact on parent functioning. Journal of Abnormal Child Psychology 1993; 21: 581-96.

16. Barkley R A, Anastopoulos A, Guevremont D C, Fletcher K E. Adolescents with attention deficit hyperactivity disorder: mother adolescent interaction, family beliefs and conflicts and maternal psychopathology. Journal of Abnormal Child Psychology 1992; 20: 263-88.

17. Goldstein S, Goldstein M. Hyperactivity: Why Won't My Child pay Attention? Wiley; New York 1992.

18. Barkley $\mathrm{R}$ A. Attention Deficit Hyperactivity Disorder: A handbook for Diagnosis and Treatment. Guilford; New York 1990.

19. Parenting practices of mothers of children with ADHD: the role of maternal and child factors. Child \& Adolescent Mental Health 2006; 11: 82-8. 